\title{
A QUASI EXPERIMENTAL STUDY OF THE TREATMENT OF ACUTE INTERNAL HAEMORRHOIDS WITH MICRONISED FLAVONOIDS AND SCLEROTHERAPY IN A TEACHING HOSPITAL OF TRIPURA
}

\author{
Surajit Kumar Das ${ }^{1}$, Sibendu Mohan Das ${ }^{2}$
}

${ }_{1}^{1}$ Associate Professor, Department of Surgery, Tripura Medical College and Dr. BRAM Teaching Hospital, Agartala, Tripura, India. ${ }^{2}$ Consultant Surgeon, Department of Surgery, Tripura Medical College and Dr. BRAM Teaching Hospital, Agartala, Tripura, India.

\section{ABSTRACT}

\section{BACKGROUND}

Haemorrhoids is a common disease affecting people of all ages and both sexes. Though there is consensus on the treatment of 3 rd and $4^{\text {th }}$ degree haemorrhoids, there is still confusion regarding the treatment of first- and second-degree haemorrhoids. Haemorrhoids [Greek; Haima-Blood, Rhoos-flowing; Synonym: Piles] (Latin: pile=a ball) are dilated veins occurring in relation to the anus. Haemorrhoids is an affliction as early as mankind itself, since man assumed an erect posture, he has been punished with a protruding painless mass at the anus.

Aims and Objectives- To compare the therapeutic efficacy of micronised flavonoids (Tab. Daflon) and Injection Sclerotherapy (5\% phenol in almond oil) in the treatment of first- and second-degree haemorrhoids of patients attending outpatient department of surgery in Tripura Medical College \& Dr. BRAM Teaching Hospital, Agartala, Tripura.

\section{MATERIALS AND METHODS}

One hundred and ten (110) patients of acute internal haemorrhoids with chief complaints of bleeding per rectum due to internal haemorrhoids were treated in outpatient department of surgery with micronised flavonoids and injection sclerotherapy from March 2018 to August 2018 and they were randomized into two groups (55 patients in each group). Patients in group A started with micronised flavonoids (Tab. Daflon $500 \mathrm{mg}$ ) and patients in group B were subjected to single peri haemorrhoidal injection with $5 \%$ phenol in almond oil. Patients were reviewed for outcome after 4 weeks.

\section{RESULTS}

At 04 weeks $48(87.30 \%)$ patients in micronized flavonoids (Tab. Daflon) and $35(63.60 \%)$ patients in injection sclerotherapy with $5 \%$ phenol in almond oil group achieved symptomatic relief from bleeding. A significant statistical association was observed between the types and outcome of treatment.

\section{CONCLUSION}

Micronised flavonoids (Tab. Daflon) gives rapid relief from symptoms of acute internal haemorrhoids and is a suitable alternative and effective non-invasive treatment in controlling bleeding in first- and second-degree haemorrhoids when compared to injection sclerotherapy.

\section{KEY WORDS}

Micronised Flavonoids (Tab. Daflon), Injection Sclerotherapy (5\% Phenol in Almond Oil), Internal Haemorrhoids.

HOW TO CITE THIS ARTICLE: Das SK, Das SM. A quasi experimental study of the treatment of acute internal haemorrhoids with micronised flavonoids and sclerotherapy in a teaching hospital of Tripura. J. Evolution Med. Dent. Sci. 2018;7(53):5597-5600, DOI: $10.14260 /$ jemds/2018/1238

\section{BACKGROUND}

Haemorrhoids [Greek; Haima-Blood, Rhoos-flowing; Synonym: Piles] (Latin: pile=a ball) are dilated veins occurring in relation to the anus. ${ }^{1}$ Haemorrhoids is an affliction as early as mankind itself, since man assumed an erect posture, he has been punished with a protruding painless mass at the anus. They have been defined as a mass of dilated tortuous veins in the anorectum involving the venous plexus of the area. ${ }^{2}$

'Financial or Other Competing Interest': None.

Submission 22-10-2018, Peer Review 17-12-2018,

Acceptance 24-12-2018, Published 31-12-2018.

Corresponding Author:

Dr. Surajit Kumar Das,

Associate Professor,

Department of Surgery,

Tripura Medical College and

Dr. BRAM Teaching Hospital

Hapania, Agartala-799014,

Tripura West, India.

E-mail: drsurajit07@gmail.com

DOI: $10.14260 /$ jemds/2018/1238

Haemorrhoidal disease is a common anorectal condition and clinically they present as bleeding per rectum, mucus discharge, prolapsed or painful defecation.

Haemorrhoids are classified in degrees depending on the symptoms as following: ${ }^{2}$

- First Degree- Haemorrhoids bleed but do not prolapse.

- $\quad$ Second Degree-Haemorrhoids prolapse on straining but reduce spontaneously.

- $\quad$ Third Degree- Haemorrhoids prolapse on straining and need manual reduction.

- Fourth Degree-Haemorrhoids are prolapsed or incarcerated.

There are many treatment options available based on the degree of the haemorrhoids, Milligan et al described haemorrhoidectomy in 1937.3 It is generally agreed that patients with either fourth- or third-degree haemorrhoids are best advised to undergo the procedure. ${ }^{4}$ There is a persistent confusion regarding the treatment options in first- and second- degree haemorrhoids. ${ }^{4}$ 
Sclerosant injection therapy (Using 5\% phenol in almond oil), Lord's Procedure, Rubber band ligation, Photocoagulation, Cryotherapy are some of the treatment modalities used for first- and second-degree haemorrhoids. ${ }^{5}$

Injection Sclerotherapy is a well-suited treatment for first- and second-degree haemorrhoids. It can be carried out on an outdoor basis and no special after treatment is required.

However, Injection Sclerotherapy is not flowless and has certain disadvantages. It is an operator skill dependent procedure and may cause bleeding and ulceration, while impotence and Prostatitis are also known complications of injection at the wrong site. ${ }^{6}$

In 1971, Daflon which is $90 \%$ Diosmin and $10 \%$ Hesperidin (Daflon 500; Serdia Pharmaceuticals, India) a flavonoid vasoprotector venotonic agent was introduced in france by Bensaude et al for the treatment of haemorrhoids and other capillo-venous diseases. ${ }^{7}$

Daflon (micronised flavonoids) is a phlebotrophic agent that increases the duration of contraction of veins, ${ }^{8}$ decreases production of prostaglandins responsible for inflammatory process. ${ }^{9}$ And increases lymphatic drainage. ${ }^{8}$ Side effects include mild gastrointestinal discomfort. ${ }^{10}$

There are very few comparative studies on therapeutic efficacy of micronised flavonoids (Tab. Daflon) and Injection Sclerotherapy (5\% phenol in almond oil) in the treatment of first- and second-degree Haemorrhoids patients. This study is therefore done to compare the therapeutic efficacy of micronised flavonoids (Tab. Daflon) and Injection Sclerotherapy in terms of reduction in bleeding per rectum.

\section{MATERIALS AND METHODS}

\section{Design of the Study}

An un-masked quasi-experimental trial was conducted in Department of surgery, Tripura Medical College \&Dr BRAM Teaching Hospital, Hapania, West Tripura, India from March 2018 to August 2018. The approval of the study was taken from the research and Ethical Committee of the Tripura Medical College \&Dr BRAM Teaching Hospital.

\section{Inclusion Criteria}

The inclusion criteria were- patient should be above 18 years of age attending outpatient department of Surgery, Tripura Medical College \&Dr BRAM Teaching Hospital, with chief complaint of bleeding per rectum because of first- and second- degree internal haemorrhoids more than three weeks with confirmation by proctoscopic examination and ready for giving consent.

\section{Exclusion Criteria}

The exclusion criteria were- known patients of inflammatory bowel disease and with other co- morbidities and haemorrhoids secondary to any other disease i.e. carcinoma rectum, pregnant ladies, patients with previous history of surgery for haemorrhoids and having haemolytic disorders.
All the patients attending in surgery outpatient department during the study period meeting the eligibility criteria were included in the present study.

A detailed history was obtained, and detailed physical examination was carried out for every subject who entered in the study as per the pre-designed proforma. Patients were examined clinically, and rectal examination was performed with the proctoscope.

Total 110 patients were included in the study and they have been distributed into two groups. (55 patients in each group)

Few baseline blood examinations like Haemoglobin estimation, total and differential leucocytic count, bleeding time, clotting time, fasting and post prandial blood sugar levels and urine complete examination were done.

The micronised flavonoids group (Group A) were started with micronised flavonoids (Tab. Daflon) 2 tablets thrice daily after meals for 3 days followed by 2 tablets twice daily from $4^{\text {th }}$ to $7^{\text {th }}$ day. On the seventh day symptoms and any relief were recorded and the dose was further decreased to 1 tablet twice daily for another 03 (Three) weeks.

The other group (Group B) were subjected to peri haemorrhoidal injection of 5\% phenol in almond oil about 3$5 \mathrm{cc}$. In this group patients were briefed about the procedure and placed in left lateral position. 5\% phenol in almond oil was taken in a disposable insulin syringe and well lubricated proctoscope was inserted gently in the rectum. Obturator is removed and proctoscope was slightly withdrawn. The pedicle of the haemorrhoid to be injected became visible. The needle of insulin syringe was inserted in the submucosal plane of the pedicle above the dentate line. Suction with needle was done to rule out any possibility of intravascular injection.

After confirmation 3-5 cc of the solution was injected into each pile in a single setting. No more than two (2) haemorrhoids were injected at a time.

All patients were treated on an outpatient basis. They were assessed for outcome on $4^{\text {th }}$ weeks after the treatment started.

The patients were labelled cured (C), improved (I), unchanged $(U)$ depending on the relief of symptoms.

Cured (C)- Absolute disappearance of symptoms.

Improved (I) - Occasional or minimal discomfort from the symptoms.

Unchanged (U) - No relief whatsoever.

The treatment was considered to be effective only if the patient said that his symptoms had been cured (C).

\section{Statistical Analysis}

The collected data were entered in Microsoft excel 2007 and analysis was done in Open software R. Categorical data were expressed in terms of frequency and percentage. Quantitative data were expressed in terms of mean and standard deviation. Chi square test were used and $p$ value of $<0.05$ was taken as significant. 


\begin{tabular}{|c|c|c|}
\hline Characteristics & Micronised Flavonoids (Tab. Daflon) & Injection Sclerotherapy 5\% Phenol in Almond Oil \\
\hline Age (in years) & $42 \pm 6$ & $44 \pm 8$ \\
Gender & $35(63.6 \%)$ & $38(69.1 \%)$ \\
Male & $20(36.4 \%)$ & $17(30.9 \%)$ \\
Female & & \\
& $30(54.5 \%)$ & $28(50.9 \%)$ \\
Severity of the Bleeding & $20(36.4 \%)$ & $24(43.6 \%)$ \\
Mild & $5(9.1 \%)$ & $3(5.5 \%)$ \\
Moderate & & $27(49.1 \%)$ \\
Severe & $35(63.6 \%)$ & $28(50.9 \%)$ \\
Proctoscopy Finding & $20(36.4 \%)$ & \\
$1^{\text {st }}$ degree haemorrhoids & Table 1. Characteristics of the Two Groups \\
\hline \multicolumn{2}{|c|}{}
\end{tabular}

In this present study the mean age in micronised flavonoid group was $42 \pm 6$ and in injection sclerotherapy $5 \%$ phenol in almond oil group was $44 \pm 8$. In both groups, males were more $(63.6 \%$ in micronised flavonoid group and $69.1 \%$ in injection sclerotherapy group). In micronised flavonoid group majority of the participants were having (54.5\%) mild bleeding and same in injection sclerotherapy group (50.9\%).

In proctoscopy examination it was found that in micronised flavonoid group majority (63.6\%) were having $1^{\text {st }}$ degree haemorrhoids and in injection sclerotherapy group majority (50.9\%) were having $2^{\text {nd }}$ degree haemorrhoids.

\begin{tabular}{|c|c|c|}
\hline $\begin{array}{c}\text { Symptomatic } \\
\text { Relief of Bleeding } \\
\text { after 4 Weeks }\end{array}$ & $\begin{array}{c}\text { Micronised } \\
\text { Flavonoids } \\
\text { (Tab. Daflon) }\end{array}$ & $\begin{array}{c}\text { Injection Sclerotherapy } \\
\text { 5\% Phenol in } \\
\text { Almond Oil }\end{array}$ \\
\hline Cured & $48(87.3 \%)$ & $35(63.6 \%)$ \\
Improved & $7(12.7 \%)$ & $18(32.7 \%)$ \\
Unchanged & - & $2(3.6 \%)$ \\
\hline
\end{tabular}

Table 2. Assessment of Symptomatic Relief of Bleeding in Both Groups after 4 Weeks

It was observed that, after 4 weeks in the present study 87.3\% were cured in micronized flavonoid group and remaining $12.7 \%$ were improved symptomatically.

In injection sclerotherapy group only $63.6 \%$ were cured and remaining $32.7 \%$ and $3.6 \%$ were improved and unchanged.

\begin{tabular}{|c|c|c|c|c|}
\hline Outcome & $\begin{array}{c}\text { Micronised } \\
\text { Flavonoids } \\
\text { (Tab. } \\
\text { Daflon) }\end{array}$ & $\begin{array}{c}\text { Injection } \\
\text { Sclerotherapy } \\
\text { 5\% Phenol in } \\
\text { Almond Oil }\end{array}$ & $\begin{array}{c}\text { Chi } \\
\text { Square } \\
\text { value } \\
\text { (df) }\end{array}$ & p value \\
\hline $\begin{array}{c}\text { Cured } \\
\text { Improved/ } \\
\text { Unchanged }\end{array}$ & 48 & 35 & & $0.295(1)$ \\
\hline Table 3. Association Between Types of Treatment and \\
Outcome \\
\hline
\end{tabular}

In this study a significant association has observed in types of treatment and the outcome (chi square $=8.285$ (1), $p$ value $=0.003)$.

\section{DISCUSSION}

Hemorrhoids are one of the most common complaints affecting in (Various forms) almost up to $50 \%$ of people over the age of fifty. ${ }^{11}$ In our study it was seen to be due to underlying genetic predisposition. Toilet habits, constipation and westernized diet are believed to be the contributing factors.

The alimentary tract terminates at the anus, which is preceded by the rectum. The complex of these two is known as anorectum. The wall of the anorectum contains the terminal branches of the superior haemorrhoidal artery in the internal haemorrhoidal plexus and the enlargement of these results in internal haemorrhoids. The three principal haemorrhoids are found at 3,7 and 11 o' clock position. ${ }^{12}$ The key point in understanding the feasibility of outpatient department is that there are no sensory nerve fibres above the dentate line (Pectinate) line in the anus which is at the submucosal junction. Internal haemorrhoids arise above that line, so they can be treated without any anaesthetic agent. External haemorrhoids develop below the dentate line are exquisitely sensitive.

There is consensus on the treatment for $3^{\text {rd }}$ and $4^{\text {th }}$ degree haemorrhoids and it is haemorrhoidectomy. The best treatment for $1^{\text {st }}$ and $2^{\text {nd }}$ degree haemorrhoids though is still an enigma. The treatment options available for internal haemorrhoids include injection sclerotherapy, Lord's procedure of anal dilatation cryotherapy, Infra-red coagulation, Laser therapy, direct electrocautery, bipolar coagulation, scalpel surgery and rubber band ligation.

micronised flavonoids (Tab. Daflon) mainly acts as an anti-inflammatory agent. It causes contraction of dilated venous plexus and local lymphatics. ${ }^{13}$ It also acts by reducing the capillary hyperpermeability and fragility. It is generally used in the treatment of acute bleeding haemorrhoids and in patients with venous insufficiency. It also has been advocated for use in first degree haemorrhoids. ${ }^{14}$ micronised flavonoids (Tab. Daflon) by the virtue of its anti-inflammatory properties, led to rapid relief from the primary complaint i.e. bleeding per rectum. The patients received the micronised flavonoids (Tab. Daflon) treatment were almost totally relieved of bleeding per rectum, which was the primary outcome measure, on $15^{\text {th }}$ day of treatment was statistically significant.

Injection sclerotherapy is an older method of treating haemorrhoids non-surgically. It is a very effective and a less tedious procedure, but it is not free from complications which can be serious sometimes. Prostatitis, Prostatic abscess, liver abscess, ${ }^{15}$ retroperitoneal sepsis ${ }^{16}$ urological complications ${ }^{17}$ was reported. Despite all these associated complications, injection sclerotherapy, because of its ease use and 
effectiveness is the widely non-surgical method of treating haemorrhoids. Fortunately, in our study none of the complications occurred.

A study conducted at Sir Gangaram Hospital, Lahore concluded that in the present day, both injection sclerotherapy and micronised flavonoids (Tab. Daflon) can be recommended for the treatment of $1^{\text {st }}$ and $2^{\text {nd }}$ degree haemorrhoids as the results were almost equivocal. ${ }^{14}$

By the end of this study, $87.30 \%$ patients in the micronised flavonoids (Tab. Daflon) group were cured and $12.7 \%$ of patients had an improved status with the treatment, while the figure for cured patients was $63.60 \%$ in case of injection sclerotherapy group (Group B) with improvement seen amongst $18.0 \%$ of patients.

\section{CONCLUSION}

We can conclude that the micronised flavonoids (Tab. Daflon) lead to rapid cessation of haemorrhoidal bleeding and gives objective relief from acute internal haemorrhoids.

In the present study, micronised flavonoids (Tab. Daflon) were very effective in the first 30 days of treatment and led to the rapid relief of various associated symptoms. Micronised flavonoids (Tab. Daflon) was more effective than injection sclerotherapy during the acute stage of the disease.

The safety of the drug has already been proved. But more studies need to be done to see if the total dose of micronised flavonoids (Tab. Daflon) can be increased so as to increase the response rate and decrease the duration of treatment.

Thus, we conclude that the micronised flavonoids (Tab. Daflon) is a suitable alternative and effective non-invasive treatment in controlling bleeding in $1^{\text {st }}$ and $2^{\text {nd }}$ degree haemorrhoids when compared to injection sclerotherapy.

\section{REFERENCES}

[1] Williams NS. The anus and the anal canal. In: William NS, Bulstrode Clk, O'Connell PR, eds. Bailey and Love Short practice of surgery. 25 th edn. London: Arnold 2004: p. 1255-62.

[2] Brisinda G. How to treat haemorrhoids. Prevention is best: haemorrhoidectomy needs skilled operators. BMJ 2000;321(7261):582-3.

[3] Milligan ETC, Morgan CN, Jones LE, et al. Surgical anatomy of the anal canal and operative treatment of haemorrhoids. Lancet 1937;2:1119-24.

[4] Mazier WP. Haemorrhoids, fissures of pruritis ani. Surg Clin North Am 1994;74(6):1277-92.
[5] Bayer I, Myslovaty C, Picovsky BM. Rubber band ligation of haemorrhoids. Convenient and economic treatment. J Clin Gastroenterol 1996;23(1):50-2.

[6] Khan N, Malik MA. Injection sclerotherapy versus electrocoagulation in the management outcome of early haemorrhoids. J Pak Medical Assoc 2006;56(12):579-82.

[7] Bensaude A, Vigale R, Naouri J. The medical treatment of acute haemorrhoidal premenstrual episodes and haemorrhoidal congestion. Lavie Medicate 19711972;52:39-45.

[8] Labrid C, Dahault J, Vix C. Pharmocological properties of Daflon 500 mg. Int J R Med 1987;85:30-5.

[9] Damom M, Flandre 0, Michel F, et al. Effect of chronic treatment with a purified flavonoid fraction on inflammatory granuloma in the rat. Study of prostaglandin E2 and F2 alpha and thromboxane B2 release and histological changes. Arzneimittelforschung (Drug Research) 1987;37(10):1149-53.

[10] Meyer OC. Safety and security of Daflon $500 \mathrm{mg}$ in venous insufficiency and in haemorrhoidal disease. Angiology 1994;45(6 Pt 2):579-84.

[11] Gordon PH, Nivatvongs S. Principles and practice of surgery for the colon, rectum and anus. $3^{\text {rd }}$ edn. New York: Informa Helath Care 2017: p. 154.

[12] Morris PJ, Malt RA. Oxford textbook of surgery. 1994;1:1127.

[13] Johanson JF, Rimma A. Optimal non-surgical treatment of haemorrhoids: a comparative analysis of infra-red coagulation, rubber band ligation and injection sclerotherapy. Am J Gastroenterology 1992;87(11):1600-6.

[14] Shaukat A, Zafar F, Aslam M, et al. Hemorrhoids. Professional Med J 2005;12:372-5.

[15] Murry-Lyon IM, Kirkham JS. Hepatic abscesses complicating injection sclerotherapy of haemorrhoids. Eur J Gastroenterol Hepatol 2001;13(8):971-2.

[16] Barewell J, Watkins RM, Lloyd-Davies E, et al. Life threatening retroperitoneal sepsis after hemorrhoidal Injection scleotherapy: report a case. Dis - Colon Rectum 1999;42(3):421-3.

[17] Al-Ghnaniem R, Leather AJ, Rennie JA. Survey of the methods of treatment of haemorrhoids and complications of injection sclerotherapy. ANN R Coll Surg Engl 2001;83(5):325-8. 